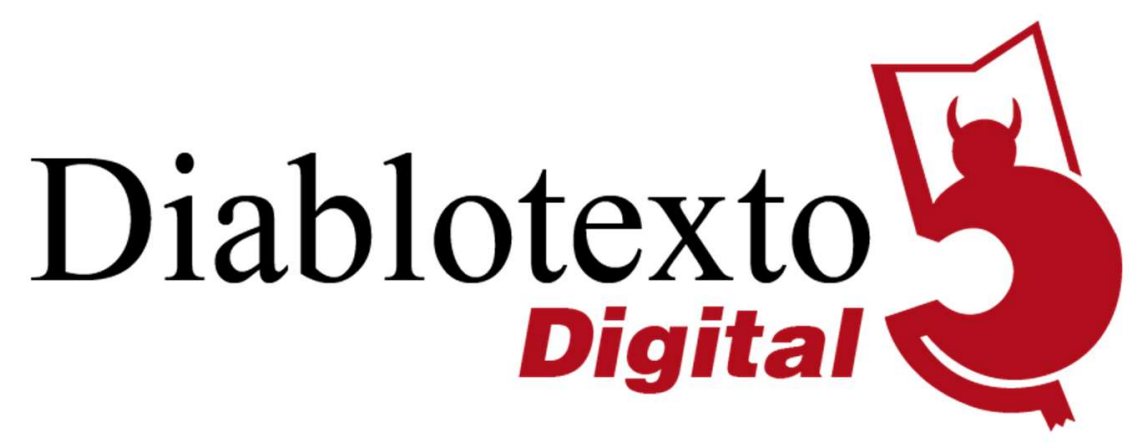

\title{
La puesta en escena contemporánea del teatro áureo: iluminación y espacio sonoro en El Caballero de Olmedo
}

Golden-age drama on contemporary stage: the role of lighting and music in El Caballero de Olmedo

AMY BERNARDI

UNIVERSITÀ DEGLI STUDI ROMA TRE

\begin{abstract}
Resumen: El presente análisis pretende estudiar el papel desempeñado por la luz y la música en las representaciones teatrales contemporáneas mediante el ejemplo concreto de algunas adaptaciones de El Caballero de Olmedo de Lope de Vega, representadas en ámbito peninsular entre 1982 y 2014 . En el estudio se destaca la estrecha vinculación de la acción representada en las tablas y el verso con la iluminación y los efectos de sonido. Lejos de ser elementos de estorbo en un teatro de palabra como el del Siglo de Oro, de hecho, iluminación y el espacio sonoro, cuando bien empleados, logran exaltar el verso de Lope sin quitarle brillo.
\end{abstract}

Palabras clave: El Caballero de Olmedo -recepción teatral-iluminación-espacio sonoro

Abstract: The following analysis aims to study the role of lighting and music in contemporary performances of Golden-age drama through some contemporary adaptations of El Caballero de Olmedo by Lope de Vega performed in Spain between 1982 and 2014. The analysis presents the strong connection between what takes place on stage and the use of lighting and music. Far from being disturbing elements in a kind of plays typically devoted to words, as Golden age dramas are, in fact, lighting and music can make Lope's verses shine -if properly used.

Key words: El Caballero de Olmedo -theatre reception-lighting-music 
El presente análisis pretende estudiar el papel desempeñado por la luz y la música en las representaciones teatrales contemporáneas del teatro áureo mediante el ejemplo de algunas versiones de El Caballero de Olmedo de Lope de Vega, montadas en ámbito peninsular entre 1982 y 2014 . Concretamente, se han examinado las grabaciones de cinco puestas en escena de la tragicomedia lopesca, archivadas en la Teatroteca del Centro de Documentación Teatral del INAEM:

1) El montaje dirigido por José Osuna, estrenado en los jardines de Las Vistillas con ocasión de la Campaña de Teatro de Verano patrocinada por el Ayuntamiento de Madrid en 1982;

2) El de Antonio Guirau, estrenado en el Real Coliseo de Carlos III de San Lorenzo de El Escorial (Madrid) en 1984;

3) El Caballero de Olmedo dirigido por Miguel Narros y estrenado en el Teatro de la Comedia de Madrid en 1990;

4) El montaje dirigido por José Pascual y estrenado en el Teatro Principal de Zamora en 2003;

5) El Caballero de Olmedo de Lluis Pasqual, estrenado en el Teatro Pavón de Madrid en $2014^{2}$.

La Teatroteca, un servicio de préstamo en línea de carácter gratuito que pone a disposición de sus usuarios una creciente selección de grabaciones en vídeo de representaciones teatrales que abarcan una parte importante de la historia reciente del teatro español (Teatroteca)

se ha revelado como un instrumento de análisis indispensable para el presente estudio. La existencia de fuentes documentales audiovisuales de carácter objetivo, según Julio Huélamo Kosma (2019: 393), bajo cuya dirección se ideó dicho servicio, permite esquivar la natural evanescencia de los montajes teatrales y dota a los investigadores del privilegio de "analizar con el mayor detalle posible los espectáculos objeto de estudio": se trata, por tanto, de unas

\footnotetext{
1 Para el presente análisis se han visionado las grabaciones de las versiones de José Osuna y Antonio Guirau que se representaron en el Teatro de Almagro, en el V y VII Festival, respectivamente.

2 Para más información sobre las puestas en escena de El Caballero de Olmedo, véase Luciano García Lorenzo, Las puestas en escena de "El Caballero de Olmedo", Olmedo, Olmedo Clásico, 2007.
} 
herramientas tecnológicas fundamentales que, "atenuando las exigencias espacio-temporales que impone el conocimiento presencial de la representación, posibilitan un grado de conocimiento muy considerable y aplicable a la valoración crítica de las producciones teatrales".

\section{lluminación}

Durante el Siglo de Oro, como es sabido, los espectáculos se montaban a primera hora de la tarde para suplir la falta de iluminación artificial en los corrales. El tablado, entoces, quedaba inundado por la luz natural y los espectadores seguían sin dificultad los movimientos de los actores, incluso cuando las acciones se desarrollaban de noche: la oscuridad, a menudo, se indicaba con la presencia de una vela o se percibía gracias a las palabras o al vestuario de los personajes. Las puestas en escena contemporáneas, por el contrario, se estrenan en teatros dotados de iluminación artificial: el mismo teatro de Almagro, a pesar de constituir un ejemplo de "beautifully conserved sixteenthcentury corral" (Wheeler, 2012: 229), ya se ha modernizado, adaptándose a acoger montajes también por la noche. Por consiguiente, las escenas que antaño eran envueltas únicamente en tinieblas simbólicas ahora han pasado a representarse en una oscuridad real y casi total, donde sólo la presencia de luces oportunamente colocadas le permite al público monitorear la acción. Sin embargo, algunas veces los focos no bastan y los espectadores tienen que esforzarse para estar al tanto de los acontecimientos que ocurren en la escena: a este respecto, José Ruano de la Haza (2001: 205) se queja frente a un realismo excesivo, que dificulta una comprensión plena de la obra representada, sosteniendo que "si las escenas de noche eran tan populares [en el Siglo de Oro, n.d.R.], es precisamente porque los dramaturgos sabían que se iban a ver con claridad meridiana; si no, las hubieran evitado".

La tipología misma del presente estudio -originado del examen puntual de grabaciones y no de la visión directa y presencial de las puestas en escenaimpide estudiar de manera exacta la colocación y la distribución de las fuentes luminosas dentro del teatro -tal como se suele recomendar a quienes aspiren a dedicarse al análisis de representaciones teatrales. Sin embargo, afortunadamente no todas las peculiaridades del empleo de las luces se pierden 
en la grabación.

En el montaje dirigido por Lluis Pasqual, por ejemplo, la compenetración entre actuación, iluminación y música alcanza niveles notables en el intermedio que separa el final del segundo acto del comienzo del tercero. Carmen Machi (que interpreta el papel de Fabia), rompiendo toda ilusión escénica, se dirige directamente a los espectadores, anunciando el tango intepretado por David Verdaguer (el Condestable) y dejándole a este la palabra. No obstante, las luces siguen iluminando a la alcahueta hasta que el mismo Verdaguer, dirigiéndose a su compañera, no le pide que le deje el foco. Sólo entonces Machi, en perfecta sintonía con el técnico de iluminación, le restituye a Verdaguer la atención de los reflectores con un movimiento significativo de la mano: la luz acompaña el gesto como por arte de magia, hechizando al público. El espectáculo ya puede empezar: el largo monólogo de don Alonso:
$¡ A y$, riguroso estado, ausencia mi enemiga, que dividiendo el alma puedes dejar la vida! ¡Cuán bien por tus efetos te llaman muerte viva, pues das vida al deseo y matas a la vista! ¡Oh, cuán piadosa fueras, si al partir de Medina la vida me quitaras como el alma me quitas!
En ti, Medina, vive aquella Inés divina, que es honra de la corte y gloria de la villa. Sus alabanzas cantan las aguas fugitivas, las aves, que la escuchan, las flores, que la imitan. Es tan bella, que tiene envidia de sí misma, pudiendo estar segura que el mismo sol la envidia; pues no la ve más bella, por su dorada cinta, ni cuando viene a España, ni cuando va a las Indias. Yo merecí quererla. ¡Dichosa mi osadía!, que es merecer sus penas 
calificar mis dichas.

Cuando pudiera verla, adorarla y servirla, la fuerza del secreto de tanto bien me priva. Cuando mi amor no fuera de fe tan pura y limpia, las perlas de sus ojos mi muerte solicitan. Llorando por mi ausencia Inés quedó aquel día, que sus lágrimas fueron de sus palabras firma.

Bien sabe aquella noche que pudiera ser mía.

Cobarde amor, ¿qué aguardas, cuando respetos miras? ¡Ay, Dios, qué gran desdicha, partir el alma y dividir la vida! (vv. 1610-1659)

se transforma en un tango maravilloso. A la voz grave de Verdaguer, arrodillado ante una Mima Riera (doña Inés) sentada en el centro del tablado, se suman el violín de Laura Aubert (Ana) y una breve exhibición de tango en el fondo del tablado.

Además, en el montaje de Pasqual, se acude a la iluminación para darle al público la impresión de presenciar -puesto que, de hecho, no se representa en la escena- la corrida donde don Alonso da muestra de su gallardía, ensombreciendo inevitablemente a don Rodrigo: el tablado se tiñe de rojo, aludiendo tanto a la sangre del toro, víctima de la destreza de los caballeros en la plaza, como a la del caballero de Olmedo que, dentro de poco, caerá víctima del arcabuz de Mendo. Mientras tanto, una luz oblicua ilumina los rostros frustrados de los caballeros de Medina, hundidos tras la derrota y la humillación sufridas en la plaza de toros. El color rojo -triste presagio del destino de don Alonso- volverá a inundar el tablado durante el último encuentro entre el forastero y doña Inés, en abierto contraste con la luz fría, casi azul, que alumbra a los dos amantes, transmitiendo al público la desesperación de un adiós definitivo.

Sobremanera sugestiva resulta, finalmente, la recreación en las tablas de la colisión entre don Alonso y la misteriosa sombra gracias a la intervención sinérgica de luces y sonidos. El caballero, acongojado tras despedirse de su amada, se ve envuelto en las tinieblas: solo una luz frontal, fría, alumbra la figura 
del actor en el tablado. A la música, acompasada y perturbadora, se unen los demás actores presentes en escena, chasqueando los dedos. El ritmo frenético infunde en el espectador la sospecha —confirmada en la escena siguiente- de que alguien esté acechando a don Alonso. Nada más emprender el camino, efectivamente, se produce un brusco cambio en la fuente de la iluminación, deslumbrando al caballero que, de repente, titubea. En la versión de Lluis Pasqual, entonces, en un primer momento la sombra no es nada más que un rápido pasaje de un tipo de iluminación frontal a otro oblicuo. Solamente tras algunos instantes, esta presencia espeluznante se presentará como don Alonso a través de una voz en off.

La adaptación de 2003, en cambio, se abre con un juego de luces que alumbra por intervalos regulares el telón de fondo, donde luce un enorme "rosetón labrado en madera" que "funciona con un valor polisémico (escudo de armas en casa de Inés, un ojo vigilante, el corazón de don Alonso...)" (Mascarell, 2013: 966).

Al igual que Lluis Pasqual, también José Pascual había recorrido a la luz roja para representar en el tablado las acciones frenéticas de la corrida: entre ruidos siniestros y gritos desasosegantes, al principio del III acto, el telón de fondo se abre, desprendiendo una nube de humo blanco que invade el escenario. Mientras tanto, en el fondo destaca un panel bermellón: el color rojo —clara señal del sacrificio del toro en la plaza— volverá a aparecer en el instante mismo en que don Alonso caiga a manos del arcabuz de Mendo.

Además, el movimiento de las luces contribuye a indicar el paso del tiempo, que se concreta en la reproducción artificial del amanecer y del atardecer y en la presencia de focos que fingen las estrellas durante el monólogo inicial de don Alonso, cuando el caballero se muestra totalmente convencido de que el amor no es más que correspondencias de estrellas.

Sin embargo, donde más destaca el papel de la iluminación es en la representación del encuentro entre el caballero de Olmedo y la misteriosa sombra que lo persigue: al volver a Olmedo, don Alonso, solo en la oscuridad, se ve asediado por las luces de reflectores enloquecidos, que parecen moverse como si estuvieran vivos. La rápida alternancia de luz y sombra, unida a la 
presencia de ruidos amenazadores, desconcierta al caballero, que intenta en vano entender lo que está ocurriendo. Análogamente, la sinergia entre iluminación y efectos de sonido contribuye de manera significativa a la escenificación del encuentro entre don Alonso y el labrador. Mientras don Rodrigo se afana por tender la emboscada al forastero enemigo, Mendo le advierte que alguien está a punto de llegar. Los hombres de Medina se esconden enseguida, listos para tender la trampa a don Alonso, pero aparece un simple labrador que, solo y asustado, vagabundea por el tablado, empuñando un bastón. Al abalanzarse sobre él, don Rodrigo y los suyos, tapados, se percatan del equívoco y huyen por las puertas a la izquierda del tablado. El pobre labrador, por tanto, ya sabe lo que se encubre más allá de esas puertas y, al acercarse don Alonso, bien puede decirle Volved atrás, no paséis deste arroyo (vv. 24092410), porque ha visto con sus ojos lo que le espera al caballero y su conocimiento del futuro ya no se basa solamente en la seguidilla escuchada de Fabia, como en el texto original. Lo acertado de la escena estriba sobre todo en la compenetración de iluminación y efectos de sonido, fundamentales a la hora de recrear esa atmósfera de angustia y desasosiego que escolta la última salida de don Alonso hacia Olmedo.

En el montaje de Miguel Narros, por el contrario, no se registra ningún expediente lumínico en el momento del encuentro entre don Alonso y la sombra: sobre el tablado, de hecho, aparece un actor de carne y hueso -como en el texto original- que, escondiéndose detrás de uno de los paneles metálicos que sustentan la escenografía de Andrea D'Odorico ${ }^{3}$, aterra al caballero de Olmedo, declarando ser nada menos que don Alonso Manrique.

Además, parece interesante subrayar la evolución de la función de la vela como objeto de escena, hoy, con respecto al siglo XVII. La escena del teatro del Siglo de Oro era una escena vacía, esquemática y simbólica. En aquella época,

\footnotetext{
3 Para más información sobre el escenógrafo italiano Andrea D'Odorico y su estrecha colaboración con el director Miguel Narros, no solamente con ocasión de la puesta en escena de El Caballero de Olmedo de 1990, véase Olivia María Nieto Yusta, Calderón de la Barca en la Compañía Nacional de Teatro Clásico (1986-2013) y la función dramatúrgica de la escenografía, tesis doctoral dirigida por José Romera Castillo, Madrid, Universidad Nacional de Educación a Distancia, Facultad de Filología, Departamento de Literatura Española y Teoría de la Literatura, 2015.
} 
de hecho, los corrales no disponían de tantos recursos como para invertir en el decorado. Los espectadores que asistían a las funciones, por tanto, se hallaban ante una evidente escasez de signos en la escena, muy distante de la abundancia de objetos que define el teatro realista, cuya ambición roza la reproducción fotográfica de la realidad. Según José María Díez Borque (1975: 54), en el siglo XVII "el signo escénico es signo de signo y no signo de cosa": el carácter simbólico y no realístico del signo, por tanto, "permite que una galería elevada (lo alto) pueda significar, por ejemplo, el mundo sobrenatural". Se trata, entonces, de un signo equívoco que el espectador interpreta de manera correcta solamente a raíz de una convención escénica consolidada, "un acuerdo tácito entre escenario y espectador" che varía de época en época (1975: 55).

Ahora bien, en el Siglo de Oro, la presencia de una vela en las tablas constituía un mensaje inequívoco para el público, que se daba cuenta enseguida de que la acción iba a ocurrir de noche. En el montaje de 1990, en cambio, la vela que doña Leonor lleva en la mano durante el último encuentro entre los dos amantes ya no es la única señal que tienen los espectadores para percatarse de que la acción se desarrolla a oscuras: la iluminación artificial sola ya permite la recreación fiel de situaciones diurnas o nocturnas, de modo que cualquier otra indicación resulta redundante. Lo mismo ocurre con el montaje de Antonio Guirau, donde aparece un candil -y no una vela, como en la puesta en escena de Narros- en sendos momentos a oscuras de la acción.

Por último, cabe destacar el papel esencial de la iluminación en la versión propuesta por José Osuna. La escenografía de Pedro Francesch divide el tablado en dos partes distintas, con el objetivo de reproducir los espacios donde se mueve don Alonso (izquierda) y la casa de doña Inés (derecha), respectivamente. Durante la puesta en escena, por consiguiente, las luces siguen de cerca la acción, iluminando alternativamente el lugar donde esta se desarrolla y ocultando el otro.

\section{Espacio sonoro}

Al igual que la iluminación, los sonidos pueden desempeñar una función considerable dentro de un montaje: según Iglesias Simón, en concreto, la música puede contribuir a la 
determinación geográfica; determinación cultural y social; determinación temporal; enfatización de la acción; representación de identidad; creación de atmósferas y ambientes y evocación de sentimientos y estados de ánimo [...] y articulación de transiciones (2016: 92).

La versión de Lluis Pasqual, por ejemplo, se abre con una escena plenaria, con todos los personajes — menos Fabia - reunidos en círculo, cantando

Una noche le mataron

al caballero,

la gala de Medina,

la flor de Olmedo.

Sombras le avisaron

que no saliese

y le aconsejaron

que no se fuese.

Una noche le mataron

al caballero,

la gal de Medina,

la flor de Olmedo (vv. 1-12).

y presagiando el destino trágico que le espera al protagonista: para Marcos Ordóñez (Ordóñez, 2014), "la polifonía del comienzo, orquestada por Dani Espasa, [...] eriza el lomo más coriáceo". La canción representa un primer ejemplo de la que Pavis (1980: 267) define "musique produite et motivée par la fiction": durante la puesta en escena, de hecho, los músicos acompañan cada melodía con su presencia en el tablado, denotando que "la mise en scène et la musique ne cherchent pas à faire illusion sur leur origine et fabrication". A menudo, los actores mismos se convierten en músicos, alternando verso y canto, como en el caso de Jordi Collet, que desempeña el papel de don Pedro y toca la guitarra de vez en cuando:

las voces y las guitarras flamencas de Pepe Motos y Antonio Sánchez (a los que se une la guitarra de Collet) subrayan los pasajes líricos, clavan sus momentos álgidos, y van alzando, con toques delicados, la atmósfera de peligro y misterio de la segunda mitad. Por otra parte, las percusiones, con cajón y pandero, añaden nervio y ritmo a las escenas de la pelea [...] y a la corrida [...] (Ordóñez, 2014).

Todos los sonidos que se escuchan durante el montaje de Pasqual, por tanto, se definen como diegéticos por ser, en palabras de Iglesias Simón (2016: 91), "pertenecientes al mundo de la ficción y originados [...] dentro [...] del espacio visible de la escena". Asimismo, el director inserta en su versión de El caballero de Olmedo dos momentos musicales originales, construidos a partir de un uso 
peculiar del texto de Lope. Este tipo de aportación no hace sino confirmar las potencialidades escénicas del espacio sonoro que, según Pablo Iglesias Simón, suelen manifestarse

en los ámbitos de la dirección de la atención, la trasmisión de significados (significación), la creación de efectos emocionales [...], para [...] predisponer la percepción, [...] las reacciones emocionales y la evaluación (deseablemente favorable) realizadas por el público como masa y el espectador como individuo (2016: 86).

Del primero, es decir, del empleo de un monólogo de don Alonso como letra de un tango argentino, ya se ha hablado anteriormente. En el segundo, en cambio, Pol López (Tello) reinterpreta a su gusto el monólogo del original:

Pues puedo hablar sin recelo,

a Fabia quiero llegar.

Traigo cierto pensamiento

para coger la cadena

a esta vieja, aunque con pena

de su astuto entendimiento.

No supo Circe, Medea,

ni Hécate, lo que ella sabe; tendrá en el alma una llave que de treinta vueltas sea.

Mas no hay maestra mejor que decirle que la quiero, que es el remedio primero para una mujer mayor;

que con dos razones tiernas de amores y voluntad, presumen de mocedad y piensa que son eternas.

Acabóse. Llego, llamo.

Fabia... Pero soy un necio; que sabrá que el oro precio y que los años desamo,

porque se lo ha de decir el de las patas de gallo (vv. 1916-1939).

mientras se desplaza de una parte a otra del tablado, mezclando rap y tango en una secuencia nueva e inmersiva y suscitando muestras de aprobación entre sus compañeros, que le rodean en el tablado. En esta escena es evidente el uso —común en las piezas del Siglo de Oro- de la técnica que Javier Rubiera Fernández denomina espacio itinerante: con este recurso, de hecho, 
se muestra [...] una escena esencialmente dinámica que tiene como resultado la transición hacia un nuevo lugar de ficción sin que los personajes hayan tenido que abandonar el tablado y volver a salir de nuevo. Al comienzo se está en un espacio $A$ y al final se está en un espacio $B$ y entre uno y otro los personajes recorren en presencia del receptor un tercer espacio durante cierto tiempo perceptible por el espectador en la representación [...], pues el personaje o los personajes hablan entonces (2005: 108).

Protagonista del espacio itinerante es, a menudo, el gracioso, "en perfecta consonancia con su papel de mediador entre personajes y con su función de enlace entre mundos diversos": esta figura, de hecho, posee cierta permeabilidad social, "que le permite circular por todos lados con asombrosa libertad y entrar hasta en los lugares más íntimos" (Rubiera Fernández, 2005: 115). Por tanto, el espacio en que se mueve el gracioso, según Fausta Antonucci (2009: 53), "cambia a medida que Tello habla, pasándose de las inmediaciones de la plaza de toros a la calle y la casa de Fabia".

Asimismo, de especial interés resulta la escenificación de la invocación al diablo por parte de Fabia, donde a las palabras de la alcahueta

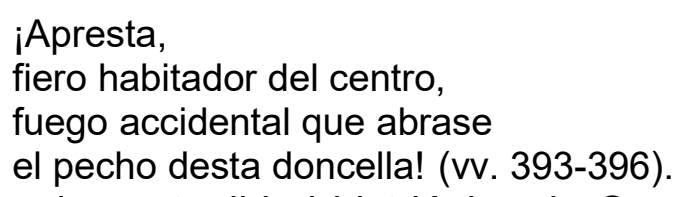

se unen la gestualidad histriónica de Carmen Machi y el ritmo frenético de las percusiones: el público presencia, entonces, un verdadero ritual con el cual la celestina de la situación pretende propiciar el enamoramiento de doña Inés por don Alonso. De hecho, del texto de Lope se deduce que este apego ya ha brotado en el pecho de la doncella, libre de todo influjo demoníaco.

Al salir del teatro, finalmente, la voz estupenda de Pepe Motos todavía resuena en las orejas de los espectadores: su interpretación apasionada de la seguidilla - primero, eco de las palabras de Fabia al final del primer acto y luego preparación del encuentro entre don Alonso y el labrador- enternece al público más terco, arrollado por aquel "lirismo de Lope" cuya fuerza, según Julio Bravo (2014), Pasqual deseaba guardar a toda costa.

Diferentemente de la adaptación de 2014, durante toda su puesta en escena, José Pascual se sirve de música producida por fuentes no visibles por los espectadores. Esta, volviendo a citar a Pavis (1980: 267), "produit une atmosphère, [...] un milieu, une situation, un état d'âme": las notas, en este caso, acompañan la acción, escoltando la entrada y la salida de los personajes y 
creando como un leitmotiv que anuncia la presencia en el tablado de una determinada figura. Además, la música acompaña los cambios escenográficos, ayudando al público a ubicarse durante los cambios de cuadro, y contribuye a "l'illustration et la création d'une atmosphère correspondant à la situation dramatique" (Pavis, 1980: 267), como en el caso de la descriptio puellae de don Alonso a principios del primer acto o en el momento en que el caballero lee en voz alta la respuesta de doña Inés a su soneto. Asimismo, cabe notar que la música que acompaña el ruego de Fabia a doña Inés

[...] Haz una cosa

por mí, doña Inés hermosa,

que es discreto pensamiento:

respóndeme a este papel,

y diré que me le ha dado

su dama (vv. 380-385)

para que conteste al papel del misterioso caballero se repite en el momento en que, después de algún tiempo, la vieja exhorta a la doncella

Déjame a mí tu suceso.

Don Alonso ha de ser tuyo;

que serás dichosa, espero,

con hombre que es en Castilla

la gala de Medina,

la flor de Olmedo (vv. 882-887)

a que confíe en sus recursos: el ritmo, en este caso, revela a una joven con los ojos abiertos de par en par, a punto de ceder ante la propuesta tentadora de Fabia, medio hechizada por sus ciencias ocultas e incapaz de divisar lo peligroso que es el confiar en una mala consejera. Según Susana Moreno Pachón, en definitiva, José Pascual logra entrelazar un "tejido compacto con luz, sonido y una escenografía que mantenga en tensión permanente al público" (2004).

Igualmente, Miguel Narros decide optar por una incidental music (Pavis, 2004: 177) a lo largo de su montaje, con mera función de acompañamiento, subrayando los cambios de escena, indicando la localización espacio-temporal de la acción dramática y señalando la aparición de sendos personajes (como en el caso del rey, cuya venida se anticipa con notas graves y solemnes). Solamente en un caso el canto se produce directamente en la escena y las actrices actúan de intérpretes y músicos a la vez: en el primer acto, en concreto, Ana, Leonor e Inés se lanzan en un baile original - ausente en el texto de Lope-, cuya letra anticipa la historia del caballero de Olmedo, revelando el final de la tragicomedia. 
Contemporáneamente, doña Inés toca el clavicémbalo, doña Leonor una pandereta, mientras que Ana se dedica al laúd.

La puesta en escena dirigida por Antonio Guirau, en cambio, se abre con la melodía de una flauta, que acompaña el monólogo de don Alonso sobre el amor. Además, el director recurre a una combinación original de luces y sonidos para encender el tablado tras la invocación al diablo de Fabia: mientras, como se ha visto, en la versión de Lluis Pasqual la música, junto con los gestos de la alcahueta, es el elemento central que convierte la apelación demoníaca en un ritual propiciatorio, en la adaptación de 1984 las palabras de Fabia desencadenan truenos y relámpagos. Leonor, asustadísima, tiembla como una hoja y no le queda otro remedio que santiguarse, invocando la protección del cielo. Asimismo, durante el segundo acto, el sonido vivaz e irónico de una flauta advierte al espectador de la trampa que se prepara en detrimento del ingenuo don Pedro, acompañando la salida al tablado de la alcahueta, disfrazada de maestra de virtudes. El tono ridículo de la situación se hace todavía más patente cuando Tello también se muestra ante el público, vestido de estudiante y acompañado por el sonido de una trompeta. En la versión de Guirau, en fin, existe una sola ocasión en que la música se origina directamente en la escena y al público se le permite ver la fuente de las notas que oye, es decir, el encuentro entre don Alonso y el labrador quien, encapuchado, toca la flauta y, al aparecer en el tablado, canta la famosa seguidilla.

Poco hay que decir sobre el papel de la música en la puesta en escena dirigida por José Osuna, puesto que, como ya se ha comentado, el director hace hincapié principalmente en la escenografía para materializar su lectura de El caballero de Olmedo. Los efectos de sonido, de hecho, se limitan a acompañar los cambios de cuadro y los momentos de mayor lirismo y no se utilizan tampoco para escenificar el eco producido por las palabras desasosegantes de la misteriosa sombra que se manifiesta ante don Alonso al volver de Medina a Olmedo.

\section{Conclusiones}

El papel de la iluminación y del espacio sonoro, en definitiva, varía de montaje a montaje. En el de Miguel Narros, luz y música desempeñan un papel 
de mero acompañamiento, casi accesorio, mientras que en la lectura de José Osuna solo a la iluminación se le atribuye una función esencial, puesto que los focos alumbran alternativamente los dos espacios donde se desarrolla la acción. En el resto de las puestas en escena analizadas, por el contrario, destaca una estrecha vinculación de la acción representada en las tablas y el verso con la iluminación y los efectos de sonido: en las versiones de Antonio Guirau, José Pascual y, sobre todo, Lluis Pasqual, de hecho, los recursos lumínicos y sonoros logran recrear atmósferas lúgubres, despedidas conmovedoras y violencias inesperadas, que permanecen grabadas de manera indeleble en la imaginación del público más atento. Lejos de ser elementos de estorbo en un teatro de palabra como el del Siglo de Oro, por tanto, iluminación y espacio sonoro cuando bien empleados - logran exaltar el verso de Lope sin quitarle brillo.

\section{BiBLIOGRAFÍA}

ANTONUCCI, Fausta (2009). "Notas sobre la función estructural y semántica de la métrica y del espacio en El Caballero de Olmedo, de Lope de Vega". En Joaquín Álvarez Barrientos, Oscar Cornago Bernal, Abraham Madroñal Durán, Carmen Menéndez-Onrubia (eds.), En buena compañía. Estudios en honor de Luciano García Lorenzo. Madrid: Consejo Superior de Investigaciones Científicas, pp. 49-57.

Bravo, Julio (2014). "El caballero de Olmedo, cocina de autor para Lope de Vega", $A B C, 07 / 02 / 2014$.

DíEZ BORQUE, José María (1975)."Aproximación semiológica a la "escena" del teatro del Siglo de Oro español". En José Ma Díez Borque, Luciano García Lorenzo (eds.), Semiología del teatro. Barcelona: Planeta, pp. 4992.

García LoRENZO, Luciano (2007). Las puestas en escena de "El Caballero de Olmedo". Olmedo: Olmedo Clásico.

HuÉlAmo Kosma, Julio (2019). "Alcance epistemológico del teatro filmado: un esbozo de análisis sobre algunas puestas en escena de La casa de Bernarda Alba". En Guillermo Laín Corona y Rocío Santiago Nogales (eds.), Cartografía teatrale en homenaje al profesor José Romera Castillo. Madrid: Visor Libros, Tomo II, pp.391-407.

IgLESIAS SIMÓN, Pablo (2016). "El espacio sonoro y el diseñador de sonido: arte y oficio". En José Romera Castillo (ed.), Teatro y música en los inicios del siglo XXI. Madrid: Editorial Verbum, pp. 80-101.

Mascarell, Purificación (2013). "El caballero de Olmedo en la Compañía Nacional de Teatro Clásico". En Alain Bègue, Emma Herrán Alonso (eds.), Pictavia aurea: actas del IX congreso de la Asociación 
internacional "Siglo de Oro" (Poitiers, 11-15 de julio de 2011), pp. 963971.

MoREno PACHÓn, Susana (2004). "Un caballero de Olmedo lleno de tensión y suspense llega al Pavón",El País, 04/02/2004

http://elpais.com/diario/2004/02/04/madrid/1075897476 850215.html [consultado el 4 de octubre de 2019].

Nieto Yusta, Olivia María (2015), Calderón de la Barca en la Compañía Nacional de Teatro Clásico (1986-2013) y la función dramatúrgica de la escenografía, tesis doctoral dirigida por José Romera Castillo, Madrid: Universidad Nacional de Educación a Distancia, Facultad de Filología, Departamento de Literatura Española y Teoría de la Literatura.

http://e-spacio.uned.es/fez/view/tesisuned:Filologia-Omnieto [consultado el 17 de marzo de 2020]

ORdóÑEZ, Marcos (2014). "Bulería y luna de Olmedo", El País, 22/04/2014.

PAVIS, Patrice (1980). Dictionnaire du Théâtre. Paris: Éditions Sociales.

PAVIS, Patrice (2004). L'analisi degli spettacoli. Teatro, mimo, danza. Teatrodanza, cinema. Trad.it. di Dario Buzzolan e Roberta Cortese. Torino: Lindau.

RUANO DE LA HAZA, José (2001). "Los investigadores modernos y la puesta en escena del teatro clásico". En Irene Pardo Molina, Antonio Serrano Agulló (eds.), En torno al teatro del Siglo de Oro. XV Jornadas de Teatro del Siglo de Oro. [Almería, del 5 al 15 de marzo de 1998]. Almería: Instituto de Estudios Almerienses, pp. 201-210.

RUBIERA FERNÁNDEZ, Javier (2005). La construcción del espacio en la comedia española del Siglo de Oro. Madrid: Arco/Libros, S.L.

VegA, Lope (de) (2002). El Caballero de Olmedo: edición de Francisco Rico. Alicante: Biblioteca Virtual Miguel de Cervantes.

WHEELER, Duncan, (2012). Golden age drama in contemporary Spain: the comedia on page, stage and screen. Cardiff: University of Wales Press.

SITOGRAFÍA

"Teatroteca", en http://teatroteca.teatro.es/opac/?locale=es\# [Fecha de consulta: 2 de octubre de 2019].

Fecha de recepción: 7 de enero de 2020

Fecha de aceptación: 20 de marzo de 2020 